\title{
Article
}

\section{Analysis of Japanese newspaper articles on genetic modification}

\author{
Ryuma Shineha, Aiko Hibino, Kazuto Kato \\ The rapid spread of technologies involving the application of "Genetic Modification (GM)" raised the \\ need for science communication on this new technology in society. To consider the communication on \\ GM in the society, an understanding of the current mass media is required. This paper shows the whole \\ picture of newspaper discourses on GM in Japan. For the Japanese public, newspapers represent one of \\ the major sources of information on GM. We subjected the two Japanese newspapers with the largest \\ circulation, the Asahi Shimbun and Yomiuri Shimbun, to an analysis of the full text of approximately \\ 4000 articles on GM published over the past to perform an assessment of the change of reportage on \\ GM. As for the most important results, our analysis shows that there are two significant shifts with \\ respect to the major topics addressed in articles on GM by Japanese newspapers.
}

\section{Introduction}

The introduction of "Genetic Modification (GM)" techniques had remarkable effects on society and raised heated controversies from the perspective of human health, environment, economics, ethics, and religion. Therefore, communication on GM in the public sphere is urgently needed.

In an analysis of communication in a society, social actors such as policies, industry, economy, culture, and the mass media must be considered. The latter is critical in that for the public, the mass media play an agenda-setting role. ${ }^{1}$ In Japan, the mass media have a particularly important function in communication with the general public and newspapers and television are the two main information sources on topics related to GM. According to a survey by $S T A F F,{ }^{2}$ approximately $60 \%$ of respondents obtained information on GM topics primarily from newspapers and television. ${ }^{3}$ Particularly, current research shows that many Japanese regard the newspaper as a more accurate, credible, and specialized information source than the television. ${ }^{4}$ In addition, most Japanese subscribe to newspapers that are delivered to their homes. Therefore, for an understanding of the public discussion of GM in Japan, an analysis of the Japanese newspaper articles on GM is required.

We chose two major Japanese newspapers, the Asahi Shimbun and Yomiuri Shimbun, as the research targets. The Asahi Shimbun and Yomiuri Shimbun have a daily circulation of approximately 8 and 10 million, respectively. This means that they are the first and second position in number of dairy circulation in Japan, and they are regarded as one of the most prestigious daily newspaper in Japan. Asahi Shimbun and Yomiuri Shimbun are read vastly by a balanced readership as regards to gender, age, occupation. ${ }^{5.6}$ Particularly, the high subscription rate among students, freelance professionals, and researchers, is an important feature of the Asahi Shimbun and Yomiuri Shimbun. The difference between the two newspapers has remained a matter of debate in Japan: the Asahi Shimbun is sometimes regarded as leftleaning and the Yomiuri Shimbun as right-leaning. Analysis of these two papers may yield some hints on the features of newspaper discourses.

In the last few years, several articles have been devoted to the study of Japanese newspaper articles on GM. These studies used content analysis and revealed a general tendency in the media coverage of biotechnology in Japan: the medical applications of GM were viewed positively while applications in agriculture tended to elicit a negative response. ${ }^{8.9}$ These findings are in accord with the results of an analysis of European media coverage of biotechnology..$^{10,11}$

However, these earlier studies failed to present the whole picture of Japanese media coverage on GM because the sample sizes were small compared to the total number of published articles on GM. In addition, the time frame covered by these reports was strictly limited and they focused on the analysis of 2 or 3 topics, e.g. the medical-, industrial-, and food application of GM. The dynamics and diversity of 


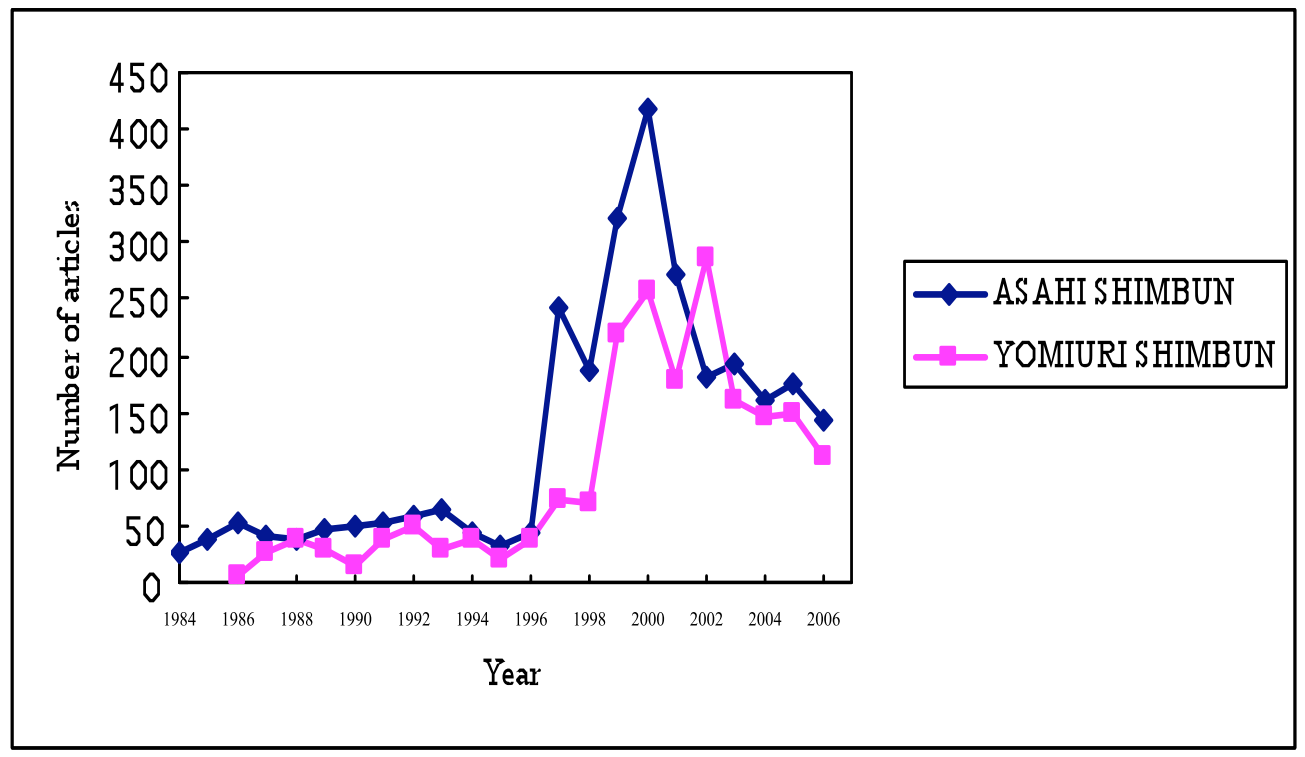

Figure 1. Number of articles on GM published over a 22-year period (1984-2006).

GM themes covered by the Japanese media remained to be analyzed. Although Hibino and Nagata examined the association among several themes and concepts and changes over time, they adopted the analytical categories applied by a European research project. ${ }^{12}$ Therefore, their study was limited with respect to biotechnology-related topics addressed by the Japanese media. Consequently, full-text analysis of article sets is not only essential in an analysis of the past and current status of Japanese newspaper coverage of GM, but is also useful for a consideration of the future direction of communication on GM.

\section{Objective}

The objective of this study was to perform a comprehensive analysis of the status and dynamics of Japanese newspaper coverage on GM. Specifically, using quantitative text analysis, this study explored the types of topics covered and the changes over time in the predominant topics. By focusing on specific words in text data, it is possible to screen a vast number of newspaper articles on GM.

\section{Method}

\section{Article collection}

We chose two major Japanese newspapers, the Asahi Shimbun and Yomiuri Shimbun, as the research targets and analyzed articles provided by both papers in Japanese language. Articles were selected with Japanese keywords: "Idenshikumikae" (meaning "Genetic Modification" and "Genetically Modified-"), "GM syokuhin" (meaning "GM food"), "GM sakumotsu" (meaning "GM crop"), "Toransujennikku" (meaning "Transgenic") and "GMO". Using the Asahi Shimbun database, ${ }^{13}$ we selected all articles that were published between 1984 and 2006 and included at least one of the keywords. Similarly, we used the Yomiuri Shimbun database, ${ }^{14}$ to examine articles published between September 1986 and 2006 that contained at least one of the keywords. Consequently, we collected a total of 4867 articles, 2886 Asahi and 1981 Yomiuri articles published in Japanese during the period covered by this study. Figure 1 shows the number of articles reviewed for each year. 


\section{Identification of topics}

The full text of all collected articles was analyzed using the $\mathrm{KH}$ Coder, ${ }^{15}$ free software for the quantitative text analysis of the Japanese language. ${ }^{16}$ It provides basic information on text data such as the occurrence rate of certain words. Using the $150 \mathrm{key}$ words with the highest frequency of use in each year we performed cluster analysis to identify the main GM topics covered in newspaper articles published in each year from 1984 to 2006. As a result, 45 high-frequency key words were identified.

\section{Multiple correspondence analysis}

Multiple correspondence analysis was conducted to investigate how specific themes were addressed by the 2 Japanese newspapers. Correspondence analysis is a descriptive/exploratory technique that uses a simple two-way and multi-way contingency table. Multiple correspondence analysis is performed on an indicator matrix that incorporates cases and categories. Articles without any of the selected key words were excluded: these included articles providing information on briefing sessions or seminars on GM foods. After their exclusion, 2,217 Asahi articles and 1,632 Yomiuri articles remained for analysis; they represented $76.8 \%$ and $82.4 \%$ of all Asahi and Yomiuri articles on GM, respectively.

Next we performed multiple correspondence analysis in which the articles represented cases and words in the categories to assess the relationship among the 45 selected key words. Calculation of the average of the case scores for each year revealed their relative position in the years under investigation. This sheds light on changes in the dominance of covered GM topics (figure 2 and figure 3 ).

Table 1 shows changes in the dominant topics with simple aggregation. Based on the results of correspondence analysis, we divided the 22-year period under investigation into 3 terms, i.e. 1984 - 1996, 1997 - 2002, and 2003 - 2006 and calculated the percentage of each covered topic vis-à-vis the total number of articles published in each term.

\begin{tabular}{|c|c|c|c|c|c|c|}
\hline & \multicolumn{3}{|c|}{ Asahi Shimbun (\%) } & \multicolumn{3}{|c|}{ Yomiuri Shimbun(\%) } \\
\hline Term & $\begin{array}{l}1984- \\
1996 \\
N=495 \\
\end{array}$ & $\begin{array}{c}1997- \\
2002 \\
\mathrm{~N}=1200\end{array}$ & $\begin{array}{l}2003- \\
2006 \\
\mathrm{~N}=522\end{array}$ & $\begin{array}{c}1984- \\
1996 \\
\mathrm{~N}=293 \\
\end{array}$ & $\begin{array}{l}1997- \\
2002 \\
\mathrm{~N}=837 \\
\end{array}$ & $\begin{array}{l}2003- \\
2006 \\
\mathrm{~N}=504\end{array}$ \\
\hline Anticipation & 15.6 & 11.4 & 7.7 & 30.4 & 16.0 & 18.7 \\
\hline Benefit & 39.4 & 25.9 & 18.2 & 41.6 & 26.5 & 22.2 \\
\hline Anxieties & 9.9 & 24.9 & 13.6 & 12.6 & 22.5 & 24.2 \\
\hline Risk & 15.8 & 13.5 & 8.1 & 12.3 & 10.2 & 12.5 \\
\hline AIDS & 9.1 & 2.7 & 0.6 & 8.5 & 3.5 & 1.0 \\
\hline Blood product & 2.4 & 1.0 & 0.0 & 2.1 & 1.0 & 0.0 \\
\hline Cancer & 4.2 & 1.6 & 0.4 & 17.8 & 1.8 & 1.4 \\
\hline Immune & 12.9 & 4.0 & 1.2 & 11.6 & 4.1 & 4.4 \\
\hline Gene therapy & 7.3 & 1.7 & 1.0 & 6.8 & 3.9 & 1.8 \\
\hline Medical application & 27.1 & 13.1 & 8.2 & 30.4 & 17.3 & 17.1 \\
\hline Mice & 7.7 & 3.3 & 5.4 & 9.2 & 5.6 & 7.9 \\
\hline Animal & 22.2 & 21.6 & 13.8 & 21.2 & 21.4 & 21.0 \\
\hline Medicine & 39.4 & 30.3 & 18.8 & 42.0 & 32.3 & 28.6 \\
\hline Genome & 1.6 & 4.6 & 2.5 & 2.7 & 7.9 & 3.8 \\
\hline Industry & 24.2 & 16.6 & 11.5 & 24.2 & 18.3 & 15.9 \\
\hline Judgment & 14.3 & 3.2 & 2.5 & 10.2 & 2.2 & 2.6 \\
\hline Micro-organism & 17.2 & 5.3 & 1.2 & 19.1 & 6.0 & 3.6 \\
\hline
\end{tabular}




\begin{tabular}{|c|c|c|c|c|c|c|}
\hline Patent & 7.5 & 4.4 & 1.9 & 10.9 & 5.7 & 2.8 \\
\hline Adverse effect on human health & 2.4 & 6.5 & 4.2 & 3.4 & 5.3 & 3.4 \\
\hline Allergy & 3.8 & 9.2 & 2.5 & 5.5 & 4.7 & 6.8 \\
\hline Corn & 3.8 & 25.3 & 7.3 & 5.1 & 23.2 & 14.9 \\
\hline Ease & 0.6 & 8.6 & 10.7 & 1.0 & 6.3 & 12.9 \\
\hline Fish & 1.0 & 4.8 & 3.5 & 3.4 & 4.4 & 2.8 \\
\hline Food self-sufficiency ratio & 0.4 & 4.1 & 2.9 & 0.0 & 3.6 & 1.8 \\
\hline Guideline & 0.0 & 2.4 & 1.2 & 0.0 & 3.2 & 1.8 \\
\hline Interfusion & 0.4 & 1.0 & 1.9 & 0.0 & 0.7 & 3.2 \\
\hline Labeling & 3.4 & 32.8 & 8.1 & 6.1 & 27.7 & 12.7 \\
\hline Maize & 3.6 & 28.4 & 14.0 & 7.2 & 21.4 & 22.0 \\
\hline Organic farming & 0.4 & 8.2 & 5.2 & 0.7 & 5.5 & 3.6 \\
\hline Safety & 38.8 & 49.3 & 30.1 & 36.9 & 47.6 & 41.7 \\
\hline Trade & 10.7 & 37.7 & 13.4 & 15.0 & 30.5 & 18.5 \\
\hline Trust & 1.0 & 3.9 & 3.1 & 1.7 & 7.2 & 6.4 \\
\hline Arabidopsis & 0.4 & 1.0 & 1.0 & 0.0 & 0.8 & 0.8 \\
\hline Biological diversity & 2.8 & 3.1 & 1.7 & 1.4 & 3.6 & 1.8 \\
\hline Diffusion & 0.4 & 0.6 & 5.8 & 0.0 & 0.8 & 7.1 \\
\hline Environment & 26.3 & 33.8 & 17.8 & 24.9 & 29.3 & 26.0 \\
\hline Field cultivation & 6.3 & 5.3 & 11.7 & 8.5 & 3.0 & 11.7 \\
\hline Flower & 3.0 & 4.3 & 5.4 & 6.5 & 5.0 & 6.0 \\
\hline Gene resource & 7.9 & 5.4 & 5.2 & 9.2 & 5.5 & 7.9 \\
\hline Rice & 9.7 & 10.4 & 16.7 & 20.1 & 10.8 & 19.6 \\
\hline Seed & 4.4 & 6.0 & 4.4 & 5.5 & 4.2 & 4.2 \\
\hline Tomato & 10.5 & 5.7 & 1.7 & 17.8 & 5.0 & 2.0 \\
\hline Public engagement & 2.0 & 4.4 & 1.3 & 1.4 & 3.5 & 2.6 \\
\hline Public opinion & 0.0 & 1.5 & 1.9 & 0.0 & 1.6 & 0.8 \\
\hline Starlink & 0.0 & 4.3 & 0.2 & 0.0 & 3.5 & 0.8 \\
\hline
\end{tabular}

Table 1. Frequency of topics $(n=45)$ addressed in each term.

\section{Results}

\section{Diversity of GM topics addressed in Japanese newspaper articles}

Figure 2 and figure 3 show the result of multiple correspondence analysis of Asahi and Yomiuri articles; they reveal the general pattern of articles on GM. Overall, the pattern for both newspapers was similar.

The covered topics were then classified into 5 main groups, i.e. Medical applications, Medicine, Food applications, Plant research, and Industrial applications. In the first quadrant in figure 2 and figure 3, "Industry", "Judgment", "Micro-organisms", and "Patent" are entered in the same cluster designated Industrial applications. In the fourth quadrant, "AIDS", "Blood products", "Cancer", "Immune", "Gene therapy", and "Medical applications" are incorporated under Medical applications. Near the Medical applications group, "Animals" and "Medicine" formed a small cluster designated Medicine. These 


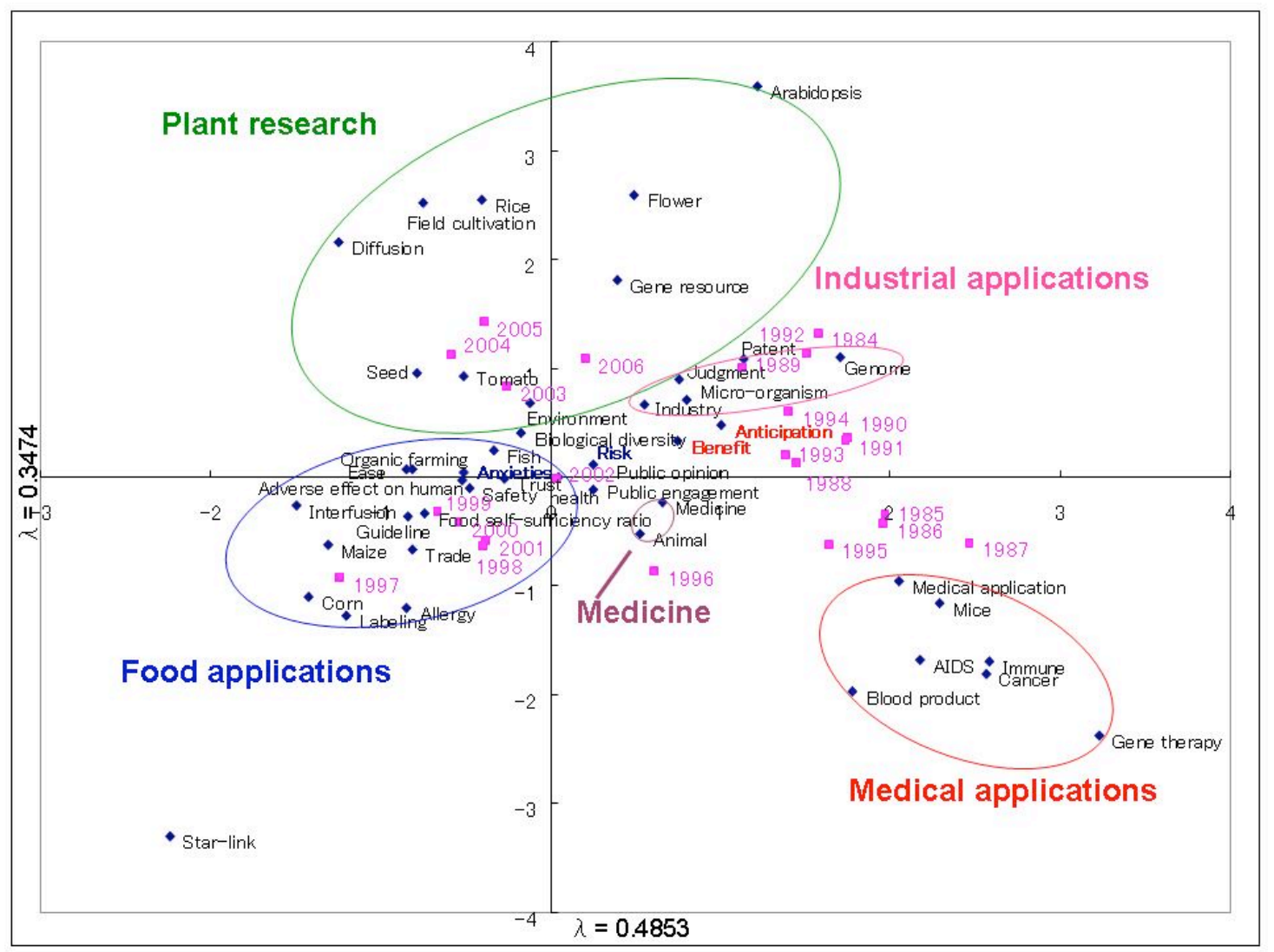

Figure 2. Correspondence between key words and groups in Asahi Shimbun articles on GM.

clusters were in close proximity to "Benefits" and "Anticipation". The third quadrant contains a large group of topics concerning imported GM foods: "Adverse effect on human health", "Allergy", "Corn", "Ease", "Fish", "Food self-sufficiency ratio", "Guidelines", "Labeling", "Maize", "Organic farming", "Safety", "Trade", and "Trust" were located near each other. This cluster was designated Food applications. The position of Food application is near "Risk" and "Anxieties". Another large cluster is Plant research; it is comprised of topics on "Arabidopsis", "Field cultivation", "Flowers", "Gene resources", "Rice", "Seeds", and "Tomatoes". "Interfusion" belongs to the Food application cluster in the Asahi Shimbun. On the other hand, in the Yomiuri Shimbun, "Interfusion" and "Diffusion" comprise a small cluster near Plant research. "Public engagement" and "Public opinion" did not show a specific pattern. "Starlink" $"$ was distantly-positioned under Food application.

\section{Shift of central topics of Japanese newspaper articles on GM}

Figure 2 and figure 3 also show the relative position of topics in the designated annual terms. The annual averages of case scores are shown as pink dots; the relative location of a center point for each year is shown. Although we plotted the topics and years on a single graph, simple Euclidian distance evaluation is not appropriate to assess the association between a specific topic and year. Care must be taken in the interpretation of the configuration of the figures and the distance between a topic and a year must be disregarded. Our results indicate that pink dots, representing the relative location of the center points for the years from 1984 to 1996, were distributed over 3 clusters, i.e. Industrial applications, Medical applications, and Medicine. During the 1997-2002 term, their position moved in the direction of the Food applications cluster. In the term 2003 - 2006, they were located near Plant research. 


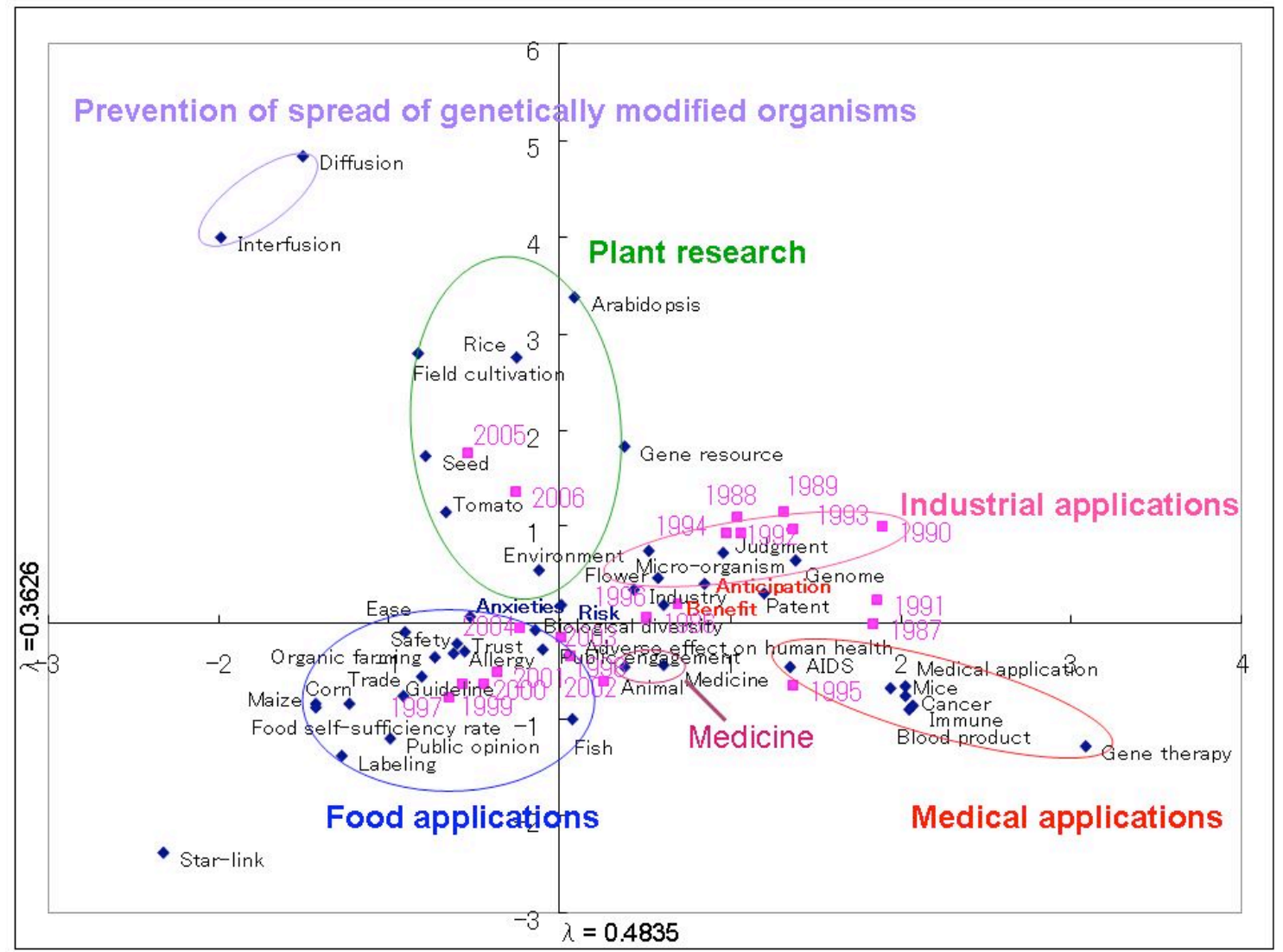

Figure 3. Correspondence between key words and groups in Yomiuri Shimbun articles on GM.

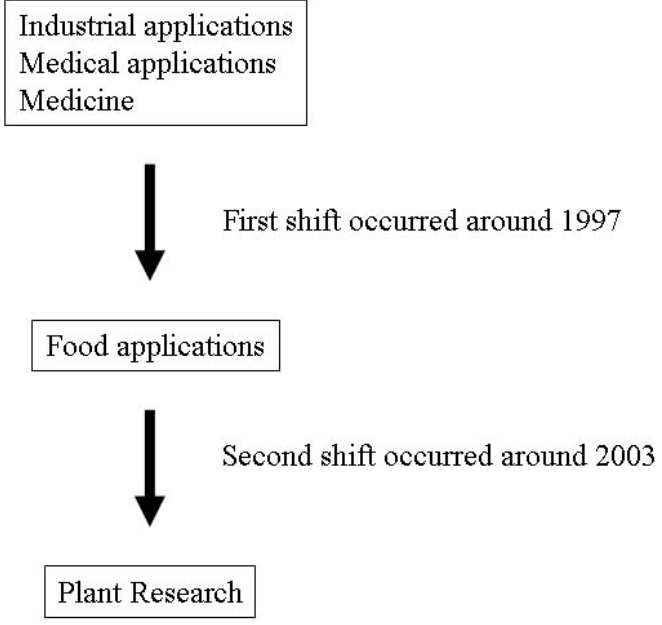

Figure 4. Shift of central topics addressed in newspaper articles on GM.

Our results demonstrate a change over time in the dominant topics covered in newspaper articles on GM. Based on the configuration of the topic clusters, the targeted terms could be divided into 3 periods, i.e. 1984 - 1996, 1997 - 2002, and 2003 - 2006. Thus, our data suggest that there were 2 significant shifts with respect to the central topics on GM covered in Japanese newspaper articles (figure 4). The first shift from Industrial/Medical applications to Food applications occurred around 1997. The second shift from 
Food applications to Plant research occurred around 2003. The shift patterns were similar for Asahi and Yomiuri articles.

To assess substantial changes in the number of articles containing the 45 key words, the percentage of each topic with respect to the total number of newspaper articles on GM in each term was calculated (table 1). The key words "Benefit", "Medical applications", "Medicine", "Industry", and "Safety" appeared often in the 1984 - 1996 term. The frequency of "Labeling", "Maize", "Corn", and "Trade" clearly increased in the 1997 - 2002 term and keywords applicable to Medical-and Industrial applications decreased. Simultaneously, the frequency of "Anxieties" and "Ease", words not used frequently in the 1984 - 1996 term, increased. Between 2003 and 2006 the frequency of the keywords "Rice" and "Field cultivation" clearly increased.

\section{Discussion and future directions}

The most important result of our study is the detection of 2 significant shifts in the central topics covered by Japanese newspaper articles on GM (figure 4). The aim of this article is not to make clear why the shift in the central topics occurred in the newspaper articles, but to describe how topics have been changing in detail. Therefore, to think about the social contexts in which newspaper topics on GM have appeared, it is useful to point out some events which occurred simultaneously in Japan as well as to explore how the newspaper topics themselves shape the changes.

The first shift, from Medical applications, Medicine, and Industrial applications to Food applications, took place around 1997. This shift coincided with a rapid increase in the number of Japanese newspaper articles addressing topics related to GM (figure 1). As a possible direct event, the Japanese Ministry of Health and Welfare approved GM soybeans, GM corn, and GM canola for human consumption in 1996. Around that time, an anti-GM foods movement started under the auspices of the Consumer Union of Japan and other organizations. ${ }^{18,19,20}$ After 1997, the negative reaction of the Japanese public to GM became apparent. ${ }^{2,14,21,22,23}$ It seems that the publication of negative articles addressing the application of GM to foods correlated with the genesis of the anti-GM movement around 1997. However, verification of the interrelated influence between the general public and media requires more detailed investigation.

The second shift occurred around 2003 when the focus of Japanese newspaper articles on GM shifted from Food applications to Plant research. Compared to the previous term, between 2003 and 2006, the frequency of articles containing the words "Labeling", "Corn", and "Trade" decreased rapidly. Typically, articles containing these key words addressed the labeling and importation of GM foods. In the preceding term, such articles tended to take a negative stance. ${ }^{24}$ Thus, this change suggests that unease with respect to GM foods expressed in Japanese newspaper articles abated in the more recent term. As shown in table 1 , the frequency of articles containing the words "Rice", "Diffusion", and "Field cultivation" increased during the 2003 - 2006 term and the frequency of other words concerning Plant research remained steady. Thus, the frequency of published articles on the field cultivation of GM crops, particularly of GM rice, increased and they typically addressed anxiety concerning the spread of GM crop pollen, possible adverse effects on the environment, and harmful rumors.

It is noteworthy that the two major shifts in topics occurred concurrently with the changes in the number of articles on GM. The first shift from Medical and Industrial to Food application corresponds with the rapid increase of numbers of whole articles on GM, while the second shift from Food applications to Plant research corresponds with the rapid drop of numbers of articles. After the second shift, the numbers of articles gradually decreased. One possible interpretation from the correspondence relation between changes in topics and number is that the second shift, focusing for Plant research, came up to the surface as a result of calming down the strong anxiety for GM foods lead by the first shift.

This paper revealed the diversity and longitudinal changes of major topics in Japanese newspaper articles addressing GM technologies. A multivariate analysis that targets keywords is appropriate for the visualization of the time-series dynamics of major topics. This method makes it easy to carry out comparisons among newspaper articles published in different countries or between different media.

To assess the global picture on the stance of the news media with respect to issues concerning GM, international comparisons of major topics and changes in newspaper coverage must be examined. Simultaneously, there is a need to examine other social realms concerning the change in domestic media discourse, taking the political and cultural context into consideration. In Japan, a few reports have 
described the political contexts and media response to events, ${ }^{25.26}$ but there are even fewer reports that identify a clear causal connection between change of media discourse and political context empirically. Hibino and Nagata pointed out the patterns of changes in the framing of biotechnology between Japan and European countries through comparative content analysis of articles on biotechnology between Japanese and European newspapers. Their study indicated that political and cultural contexts effected framings of media discourses on biotechnology in each country.

We posit that the debate regarding GM foods will continue in the future. The CODEX Alimentarius Commission has discussed the enactment of international guidelines concerning Food applications of GM animals. This topic will be of interest to Japanese society and the participation of the mass media can be expected. It is necessary to observe response of the media and the public to this discussion carefully.

Our study showed that Japanese newspaper articles addressing GM in connection with Medical applications, Medicine, and Industrial applications tend to contain positive words such as "Benefits" and "Anticipation", while articles on GM Food applications tend to contain words like "Risks" and "Anxiety". Thus, while the Medical/Industrial applications of GM technology tend to be reported affirmatively, issues related to GM Food applications elicit a cautious response by the authors of newspaper articles. Our study explored the variety of topics addressed in the public discussion of the application of GM technologies. To assess the tone of the arguments presented in Japanese newspapers, a different approach is needed. We are in the process of performing an analysis that explores keywords and particular phrases that reveal the tone of an argument using a qualitative study approach.

\section{Acknowledgement}

Authors would like to thanks for helpful comment by Dr. D. Dalsky and U. Petralia. This work was supported by KAKENHI (Grant-in-Aid for Scientific Research) on Priority Areas "Applied Genomics" from the Ministry of Education, Culture, Sports, Science and Technology to Kazuto Kato, and "Research and Development for Deliberation and Cooperation between Citizens and Scientists" from the Research Institute for Science and Technology for Society, Japan Science and Technology Agency of Japan to Dr. Hideyuki Hirakawa (Kazuto Kato is a cooperated researcher).

\section{Notes and references}

1 M.E. McCombs and D.L. Shaw, Agenda-Setting Function Of Mass Media, Public Opinion Quarterly 36 (1972) 176.

2 Society for Techno-innovation of Agriculture, Forestry and Fisheries (STAFF); organization for promoting innovations and applications of biotechnology to agriculture, forestry, and fisheries. STAFF conducted several investigations for the public; questionnaires and focus group interviews concerning genetically modified organisms.

3 STAFF (2006). Report of STAFF (in Japanese), available at: http://web.staff.or.jp/data/ivent/200603/20-2006032211531309821.pdf

4 Japan Institute for Social and Economic Affairs (2007), Report (in Japanese), available at: http://www.kkc.or.jp/society/survey/enq 070626.pdf

5 http://adv.asahi.com/2008/download/reader.html

6 http://adv.yomiuri.co.jp/yomiuri/dokudata/t-syoku.html

7 This feature is not seen in other famous Japanese newspaper (ex. Mainichi Shimbun, Nihon Keizai Shimbun).

8 T. Tsujita and R.B. Haklak, Attitude and Aspect for Biomedical Articles of 4 Biggest Newspapers in Japan, (in Japanese) Politics of BioMedical Research 1 (2003)14.

9 A. Hibino and M. Nagata, Biotechnology in the Japanese Media - Comparative Analysis of Newspaper Articles on Genetic Engineering between Japan and Europe, Asian Journal of Social Psychology 9 (2006) 12.

10 M.W. Bauer, Controversial Medical and Agri-food biotechnology: A Cultivation Analysis, Public Understanding of Science 11 (2002) 93. 
11 L.A. Marks et al., Mass Media Framing of Biotechnology News, Public Understanding of Science 16 (2007) 183.

12 M.W. Bauer, J. Durant, G. Gaskell, M. Liakopoulos and E. Bridgeman, United Kingdom, in: J. Durant, M. Bauer and G. Gaskell eds., Biotechnology in the Public Sphere: A European Source Book, (1998) page 162-176, London, Science Museum.

13 Kikuzou2 Visual for Libraries, URL: http://database.asahi.com/library2/

14 Yomidas Bunsyokan, URL: https://db.yomiuri.co.jp/bunshokan/

15 http://khc.sourceforge.net/

16 The software provides a morphologic analysis that facilitates separating Japanese text into fragments of words, e.g., nouns or verbs.

17 Starlink corn is one of several kinds of Bt corn that have been genetically engineered to produce insecticide within the plant itself so that external applications of pesticides to fields can be reduced or eliminated.

${ }^{18}$ K. Ichikawa, Genetically Modified Food and Food Labeling, (in Japanese) Journal of Nagoya Bunri University (2002) page 101.

19 M. Nishizawa, The Influence of Newspaper Articles on Risk Perception of Genetically Modified Food in Japan, (in Japanese) Journal of Science and Technology Studies 4 (2006) 118.

${ }^{20}$ Y. Sasa and K. Watanabe, The Present Situation of the Public Acceptance in Genetically Modified Crops and Food Products, (in Japanese) Breeding research 8 (2006) 99.

21 D. Macer and M.A.C. Ng, Changing Attitudes to Biotechnology in Japan, Nature Biotechnology 18 (2000) 945.

22 M.A.C. Ng, T. Watanabe and D. Macer, Attitudes of the Public and Scientists to Biotechnology in Japan at the Start of 2000, EUBIOS Journal of Asian and International Bioethics 10 (2000) 106.

${ }^{23}$ M. Inaba and D.R.J. Macer, Attitudes to Biotechnology in Japan in 2003, EUBIOS Journal of Asian and International Bioethics 13 (2003) 78.

24 The words are highly correlated with "Anxiety".

25 N.W. Kazuo, S. Yoshiko, S. Eiko, C. Chia-Hson, I. Masakazu, K. Akira, Global political, economic, social and technological issues on transgenic crops, Plant Biotechnology 22 (2005) 515.

${ }^{26}$ M. Matsuo, H. Shiroyama and T. Imamura, Low level presence of unauthorized GM plant material in food: an analysis on the past cases, (in Japanese) Food Sanitation Research 58 (2008) 27.

\section{Authors}

Ryuma Shineha is the student of the graduate school of Biostudies, Kyoto University. He is interested in social aspect of science and analyzed discourses concerning science, particularly discourses concerning genetic modification. E-mail: shineha@lif.kyoto-u.ac.jp.

Aiko Hibino is a postdoctoral fellow at the Institute for Research in Humanities, Kyoto University. She has been taking part in projects and research activities on media coverage, policy making and public perceptions of biotechnology. E-mail: Aiko.Hibino@d01.mbox.media.kyoto-u.ac.jp.

Kazuto Kato is Associate Professor of Science Communication and Bioethics at the Institute for Research in Humanities and Graduate School of Biostudies, Kyoto University. He works on the ethical and social issues of bioscience including genomics and stem cell research. E-mail: kato@zinbun.kyoto-u.ac.jp. 